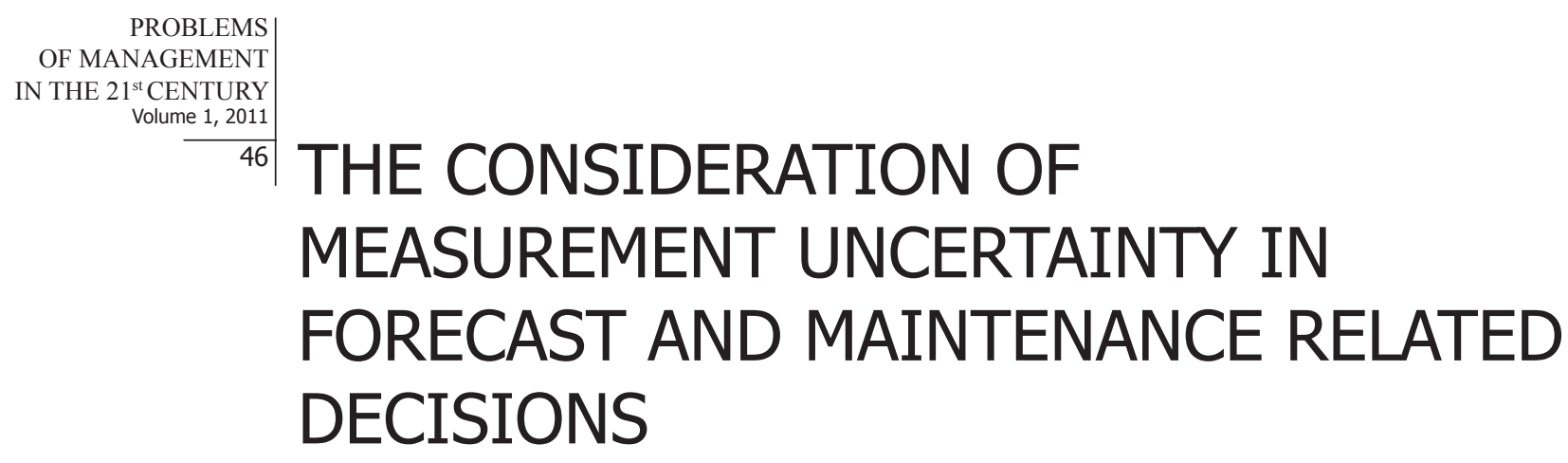

\author{
Csaba Hegedüs, Zsolt T. Kosztyán \\ University of Pannonia, Veszprém, Hungary \\ E-mail: hegeduscs@gtk.uni-pannon.hu, kzst@vision.vein.hu
}

\begin{abstract}
In the field of operations management, most decisions are seen as being based on measurement results. However, every measurement has some uncertainty and therefore managerial decisions can be incorrect. Measurement uncertainty can cause particularly large losses in the case of maintenance decisions, where decision error can cause the breakdown of the entire production or service process. Taking measurement uncertainty into consideration the losses can be decreased. The standards, technical reports and guides dealing with measurement uncertainty use probability approach and focus on the metrology aspect. They do not support a risk based decision based on the forecast of the observed characteristics. In the proposed risk based model the realized (or lost) revenue is treated along with the occurred costs in order to maximize the profit with the help of analytic calculation and simulations. This paper suggests that by treating measurement results as a time series the time of probable failure can be predicted at a given confidence level, this can support the scheduling of maintenance tasks. The uncertainty of measurement and the uncertainty of forecasting can be treated in the same model.
\end{abstract}

Key words: forecast, measurement uncertainty, risk-based maintenance, stochastic process.

\title{
Introduction
}

In preventive maintenance a conclusion is drawn about the future based on actual measured values: What will be the next value of the observed characteristic? When will the failure occur? These questions cannot be answered when using traditional conformity control. Since the measured values are not independent of the previous ones the future values are predictable with the use of time series (Kosztyán, Csizmadia, Hegedüs and Kovács, 2009; Pintelton and Schoukens, 2006). However, in the use of time series the measurement uncertainty is not taken into account or it is not separated from the uncertainty, treated as part of the white noise.

Every measurement is subject to some uncertainty that must be defined and expressed in order to make the measurement results explicit (BIPM, IEC, IFCC, ISO, IUPAP and OIML, 1993). The Guide to the Expression of Uncertainty in Measurement (GUM) proposes methods to evaluate and express this uncertainty in a uniform way. However, GUM does not give any suggestions about how to decide about the conformity of a product or a process on the basis of uncertainty. Following the GUM many studies discussing this problem have been published. Forbes (2006) approaches the conformance assessment as a Bayesian-decision, where the costs of wrong decisions are taken into account. Pendrill (2006) emphasizes that the impact of decisions should be kept to the fore at the specification of maximum permissible errors. For the correct calculation of risks the measurement uncertainty must be treated in a probabilistic approach (Rossi and Crenna, 2006). According to previous studies the consideration of measure- 
ment uncertainty has advantages not only in the case when this uncertainty is high (Kosztyán Volume 1, 2011 and Schanda, 2006) but also in cases when the consequences of a decision error (type I or type II) are significant (Arunraj and Maiti, 2009). Treating measurement uncertainty has vital importance in the area of maintenance where the failure of a device can cause the halt of the whole production or service (Krishnasamy, Khan and Haddara, 2005).

\section{Research Focus}

The studies dealing with measurement uncertainty take only the costs into account and try to minimize them. They oppose the producer's risk and the customer's risk. Kosztyán, Csizmadia, Hegedüs and Kovács (2010) have already shown that by taking revenues into consideration the two points of view can be integrated, and the producer's profit can be maximized. These revenues also depend on the decisions.

The main purpose of this research is developing a model and method to take into account the measurement uncertainty in conformity and maintenance decisions. The searched method minimizes the risk of these decisions with the consideration of measurement uncertainty and can be combined with forecasting methods. The intention of the authors is to provide a tool to the managers that helps the decisions in conformity assessment and the scheduling of maintenance tasks by determining when the control should be performed.

\section{Background}

According to the methods proposed by the GUM, the uncertainty can be expressed in two ways. On the one hand, the measurement uncertainty can be expressed as a probability distribution of measurement results described by the value of standard deviation (standard uncertainty). If the measurement result is obtained from the values of a number of other quantities the standard deviation is called combined standard uncertainty. On the other hand, the uncertainty can be described as an interval, the length of the interval calculated as a multiplication of the combined standard uncertainty and a $k$ coverage factor. The value of $k$ determined by the confidence level and the type of the probability distribution function, but it is often specified as 2 or 3 (Ellison and Williams, 2007; ISO, 1998; ILAC, 2009). This approach assumes the symmetry of the probability distribution, but this assumption is not valid in every case. This is why in the suggested model a $k_{\text {LSL }}$ lower and a $k_{\text {USL }}$ upper values are used instead of $k$ and these new altered coverage factors are determined not by the reliability but by the risk of decisions (Figure 1). In this way instead of measuring points, measuring intervals are taken into consideration between the specification limits. It is an equivalent solution if instead of using intervals new limits (critical values) are set for the decision. Since the alteration of limits depends not only on standard deviation of measurement uncertainty but also the type of the probability distribution and the consequence of decisions the $K_{\mathrm{LSL}}$ and $K_{\mathrm{USL}}$ correction factors are used subsequently. These factors give the total length and direction of the offset of specifications limits.
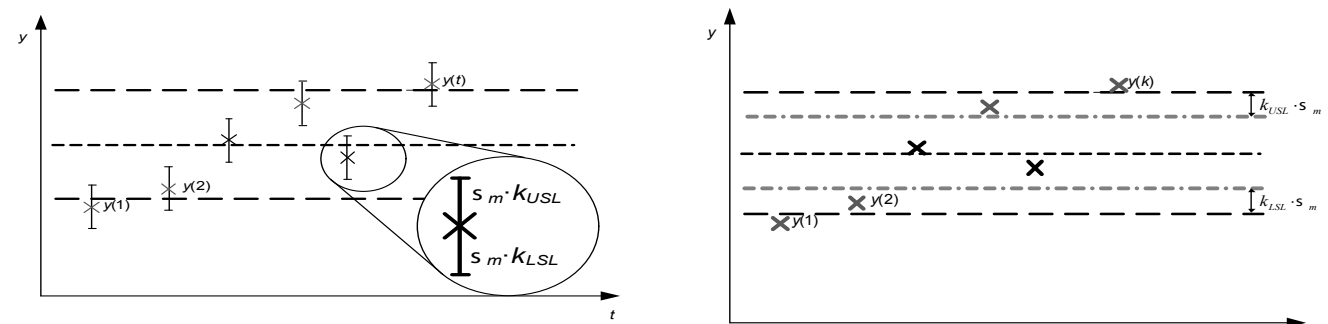

Figure 1: Decision-making of adequacy based on measuring intervals instead of measuring points and the alteration of limits as an equivalent solution. 
The change of the observed characteristic can be analysed in several ways. It can be treated as a sequence of various states identified by artificial neural networks (Chen, $\mathrm{Lu}$, and Lam, 2007) and the probability of transition between two states can be calculated. The actual state of the process of the characteristic can be specified based on the measured values of the characteristic and the previous observations. The time in the process is in this state and the most probable state into which it switches after that can be determined from the probability of the transitions. If the actual or the most probable subsequent state of the characteristic threatens the operation of device or process maintenance is necessary.

There is another way to handle the change of characteristic, its values are treated as a time series and can be studied in time-domain or frequency-domain. The stationary or quasistationary time series can be described with an autoregressive integrated moving average (ARIMA) model (Pintelton and Shoukens, 2006; Åkesson and Toivonen, 2006). This is the model that is combined with the consideration of measurement uncertainty. The ARIMA model is the generalisation of autoregressive moving average (ARMA) model for $d$ ordered integrated process. AR $(p)$ is the $p$ ordered autoregressive and $\operatorname{MA}(q)$ is the $q$ ordered moving average process. $\operatorname{ARMA}(p, q)$ is the combination of $\operatorname{AR}(p)$ and $\mathrm{MA}(q)$ process (see Eq. 1-2).

$$
\begin{gathered}
A\left(p^{-1}\right) y(k)=C\left(q^{-1}\right) e(k) \\
a_{0} y(k)+a_{1} y(k-1)+\ldots+a_{p} y(k-p)=c_{0} e(k)+c_{1} e(k-1)+\ldots+c_{q} e(k-q)
\end{gathered}
$$

To determine the order of AR and MA the autocorrelation function (ACF) and the partial autocorrelation function (PACF) are considered. There are simple rules that show the estimation of orders of ARMA process. However, there is no rule how to determine the order of ARMA when ACF and PACF functions are cutting off or decaying at same time.

- ACF: decays, PACF: cuts off $=\mathrm{AR}(p=$ cut off)

- ACF: cuts off, PACF: decays $=$ MA $(q=$ cut off $)$

- ACF: decays, PACF: decays $=$ Problem

- ACF: cuts off, PACF: cuts off $=$ Problem

When estimating the orders of ARIMA process the simplest and significant model is selected, where the coefficients of AR and MA processes are also significant.

\section{Methodology of Research}

Monte Carlo simulations and analytical calculations will be used to determine the optimal modification of the control limits based on the consideration of measurement uncertainty. After that this model will be combined with stochastic time series models in order to forecast the future values of the observed characteristic, the expected (point of) time of the failure and the risk of failure.

\section{Simulations}

For the simulation it is assumed, that the probability distribution (with its parameters) of $x$ real value of observed characteristic and probability distribution of $m$ measurement error from the calibration report are known. The decision on the conformity of process, device or product based on $y=x+m$ measured value as a sum of the real value and measurement error. The process is considered as conform if the observed value is between the LSL lower and USL upper specification limit, $\mathrm{LSL} \leq y \leq \mathrm{USL}$. If there is only one specification limit, the other limit can be ignored in the model. The process is conforming if the $x$ real value of observed characteristic is 
between the specification limits, $\mathrm{LSL} \leq x \leq \mathrm{USL}$.

Because of the measurement uncertainty four cases can be distinguished as a combination of real conformity and the decision itself (Table 1). If control or maintenance is not required, but the measured value shows the inverse, unnecessary control is done (producer's risk) and decision error type I is made. If the real value of observed characteristic is non-conforming but it is undetected because of the measurement uncertainty (customer's risk) and decision error type II is made. Also appropriate decisions can be made, if non-conform process gets controlled or conform process is let run.

Table 1. Profits influenced by the decisions and the facts.

\begin{tabular}{|ll|l|l|}
\hline \multirow{2}{*}{ Profit/Loss } & $\begin{array}{l}\text { Decision } \\
\text { Maintenance/Control is not } \\
\text { performed (1) }\end{array}$ & $\begin{array}{l}\text { Maintenance/Control } \\
\text { is performed (0) }\end{array}$ \\
\hline \multirow{3}{*}{ Fact } & $\begin{array}{l}\text { Maintenance/Control is not } \\
\text { required(1) }\end{array}$ & $\begin{array}{l}\pi_{11}=r_{11}-c_{11} \\
\text { Appropriate acceptance }\end{array}$ & $\begin{array}{l}\pi_{10}=r_{10}-c_{10} \\
\text { Inappropriate control }\end{array}$ \\
\cline { 2 - 4 } & $\begin{array}{l}\text { Maintenance/Control is } \\
\text { required (0) }\end{array}$ & $\begin{array}{l}\pi_{01}=r_{01}-c_{01} \\
\text { Inappropriate acceptance }\end{array}$ & $\begin{array}{l}\pi_{00}=r_{00}-c_{00} \\
\text { Appropriate control }\end{array}$ \\
\hline
\end{tabular}

In the four cases the $c_{i j}$ costs are different. These costs depend on the number of executed measurement, the cost of production of service or product and the actions in accordance with the decisions. In order to calculate the unrealized profit an alternative decision is made the $r_{i j}$ revenues must also be taken into account beside the costs. So $\pi_{i j}=r_{i j}-c_{i j}$ proportional profits are used to calculate the $\Sigma \Pi$ total profit in reference to decisions:

$$
\sum \Pi=q_{11} \cdot \pi_{11}+q_{10} \cdot \pi_{10}+q_{01} \cdot \pi_{01}+q_{00} \cdot \pi_{00}
$$

The $q_{i j}$ number of element belongs to certain cases calculated in the simulation.

To maximize the expected profit the decision rules should be modified: the process will be treated as conform if LSL $+K_{\mathrm{LSL}} \leq y \leq \mathrm{USL}-K_{\mathrm{USL}}$ where $K_{\mathrm{LSL}}$ and $K_{\mathrm{USL}}$ the correction factors belong to the LSL and USL. The value of correction factors are calculated in the simulation. These correction factors are not coefficients; they give directly the extent of the alteration of specification limits. If the risk of decision error type II is low the value of correction factor can be negative, in this case the control limits do not become stricter but wider. The Monte Carlo simulation searches the value of $K_{\mathrm{LSL}}$ and $K_{\mathrm{USL}}$ that result the maximum of total profit in reference to decisions.

$$
\begin{aligned}
& \sum \Pi\left(K_{L S L}, K_{U S L}\right)=q_{I I}\left(K_{L S L}, K_{U S L}\right) \cdot \pi_{I I}+q_{10}\left(K_{L S L}, K_{U S I}\right) \cdot \pi_{10}+ \\
& +q_{O I}\left(K_{L S L}, K_{U S L}\right) \cdot \pi_{O I}+q_{O O}\left(K_{L S I}, K_{U S L}\right) \cdot \pi_{O O} \rightarrow \max
\end{aligned}
$$

In the maintenance of a device the revenue cannot be interpreted in every case, that is why only costs are used to express consequences. The cost can include the costs of inspection, control and failure or the loss of unutilized productivity. This modification does not alter the structure of model but the value of $r_{i j}$ revenues will be zero. 
PROBLEMS

OF MANAGEMENT

IN THE $21^{\text {st }}$ CENTURY

Volume 1, 2011

50

\section{Analytic Calculation of Risks}

Let the probability density function of $x$ real values be $f(x)$, and the probability density function of $m$ measurement error be $g(m)$. It is assumed that these two distributions are independent of each other, and the common distribution is calculated as its multiplication. On the left side of Figure 2 the four cases of Table 1 can be seen: the parallelogram in the middle is the region of appropriate acceptance bounded by the $y=\mathrm{LSL}, y=\mathrm{USL}, x=\mathrm{LSL}$ and $x=\mathrm{USL}$ lines. Above and below this parallelogram are the regions of decision error type I, on the left and the right side between the $y=\mathrm{LSL}$ and $y=\mathrm{USL}$ lines are the regions of decision error type II. The uncoloured regions belong to the appropriate control.
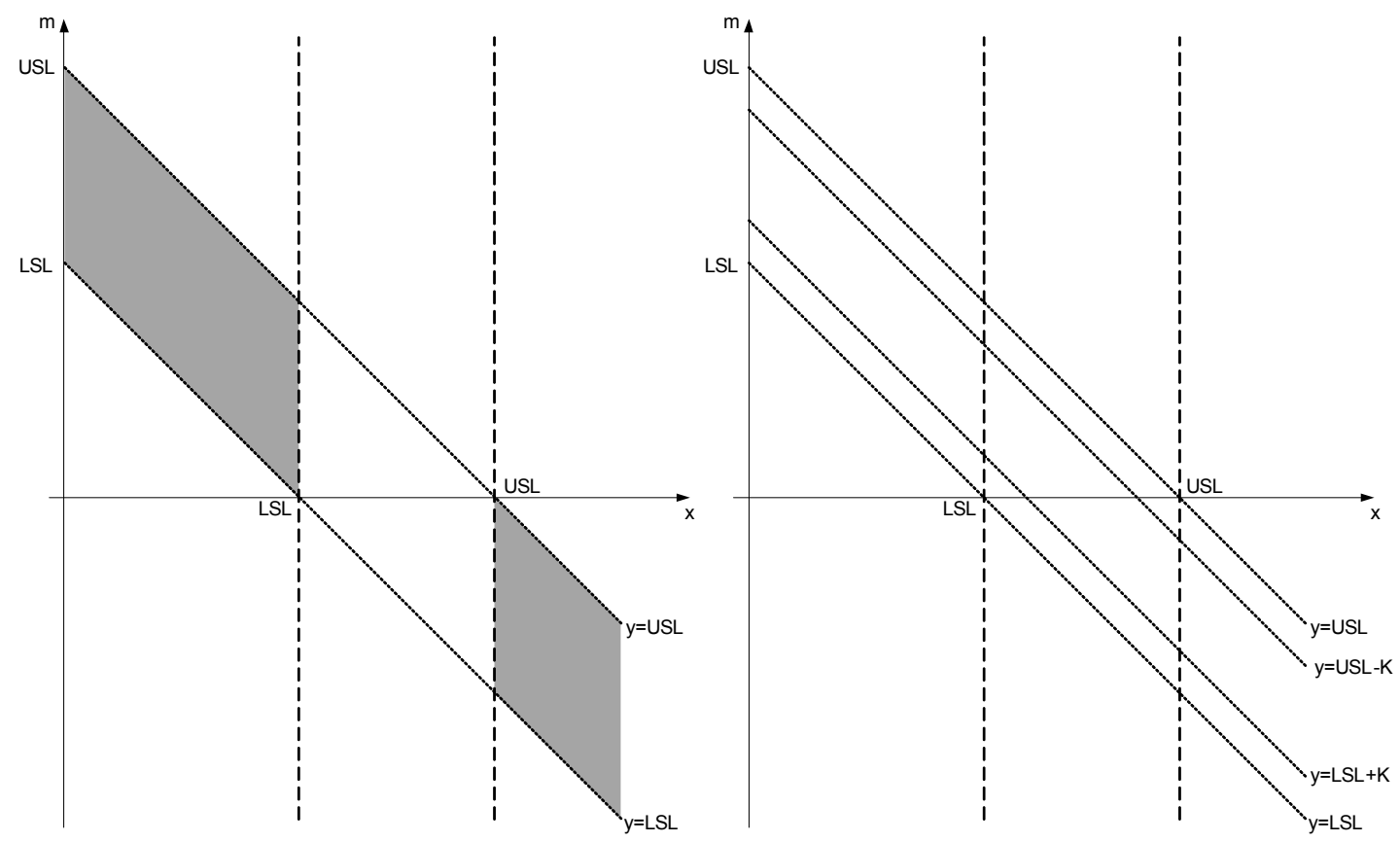

Figure 2: The 4 regions of decision outputs (left side) and the modification of these regions (right side).

The control limits and decisions must be modified in order to maximize the profit similarly to the simulation. For the sake of simplicity let the $K_{L S L}=K_{U S L}=K$ that is the lower and upper limit be modified to the same extent. If the profits belong to certain cases are weighted with the probability of occurrence, the profit maximizing target function is the following:

$$
\Pi(K)=\Pi(0)+\Delta \Pi(K) \rightarrow \max
$$

The $\Pi(0)$ is the expected profit without any modification $(K=0)$ and the $\Delta \Pi(K)$ is the increase (or decrease) of the expected profit as a function of $K$. The $\Pi(K)$ is similar to risk, because a probability is multiplied with consequence in terms of money, but the negative implications of risk, the term of expected profit is used. To maximize the expected profit it is sufficient to maximize $\Delta \Pi(K)$ (right side of Figure 2): 
Csaba HEGEDŰS, Zsolt T. KOSZTYÁN. The Consideration of Measurement Uncertainty in Forecast and Maintenance Related Decisions
PROBLEMS
(6)
Volume 1, 2011

Where deterioration appears and there is a trend in the observed characteristic it is suf-

$$
\begin{aligned}
& \Delta \Pi(k)=\left(\pi_{00}-\pi_{0 I}\right) \int_{-\infty}^{L S L}\left[\int_{L S L-x}^{L S I+Z-x} f(x) g(m) d m+\int_{U S L-K-x}^{U S L-x} f(x) g(m) d m\right] d x+ \\
& +\left(\pi_{I 0}-\pi_{I I}\right) \int_{L S L}^{U S L}\left[\int_{L S L-x}^{L S L+K-x} f(x) g(m) d m+\int_{U S L-K-x}^{U S L-x} f(x) g(m) d m\right] d x+ \\
& +\left(\pi_{00}-\pi_{O I}\right) \int_{U S L}^{\infty}\left[\int_{L S L-x}^{L S L+K-x} f(x) g(m) d m+\int_{U S L-K-x}^{U S L-x} f(x) g(m) d m\right] d x \rightarrow \max
\end{aligned}
$$

ficient to take into consideration only the specification limit to the tendency of the trend. In those cases when only a minimum or only a maximum value is determined that must not be exceeded by observed characteristic, this limit must be taken into consideration in the course of decision making. If there is only LSL the regions belong to $\Delta \Pi(K)$ are similar to the region in Figure 3.

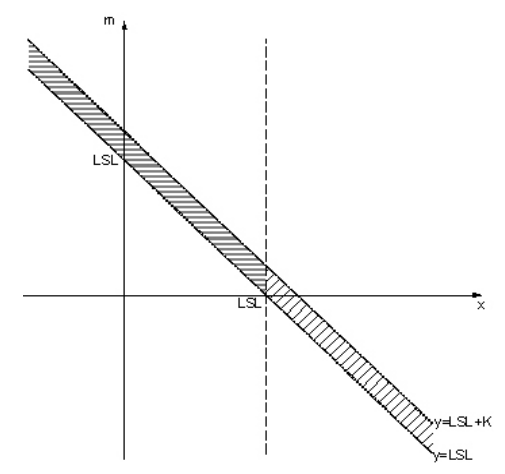

\section{Figure 3: The region of $\Delta \Pi(K)$ in case of only LSL exists.}

All the points above the $y=\mathrm{LSL}+K$ line are in the accepting region but only the points right of the $x=\mathrm{LSL}$ vertical line actually conform. Under the $y=\mathrm{LSL}+K$ line the maintenance is executed, but it should be done only if $x<$ LSL. The increase of profit is calculated with the Eq. (7).

$$
\begin{aligned}
& \Delta \Pi(k)=\left(\pi_{00}-\pi_{0 I}\right) \int_{-\infty}^{L S I} \int_{L S L-x}^{L S I+K-x} f(x) g(m) d m d x+ \\
& +\left(\pi_{10}-\pi_{I I}\right) \int_{L S L}^{\infty} \int_{L S L-x}^{L S L+K-x} f(x) g(m) d m d x \rightarrow \max
\end{aligned}
$$

\section{Forecasting}

If deterioration occurs, the process of the observed characteristic of the device has a trend and therefore it is suitable to handle the process as a time series. In order to treat the 
PROBLEMS

OF MANAGEMENT

IN THE $21^{\text {st }}$ CENTURY

Volume 1, 2011

52 time series of the observed characteristic with linear stochastic models the time series must be decomposed. The trend shows the expected value of the characteristic. The uncertainty of this forecast derived from the random variation of real value, the frequency of sampling, the sample size and the time interval of the forecast. If the intervals between the samplings are equal the width of the confidence interval of the trend is constant. The lower and upper bound of confidence interval parallel to the trend (left side of Figure 4).
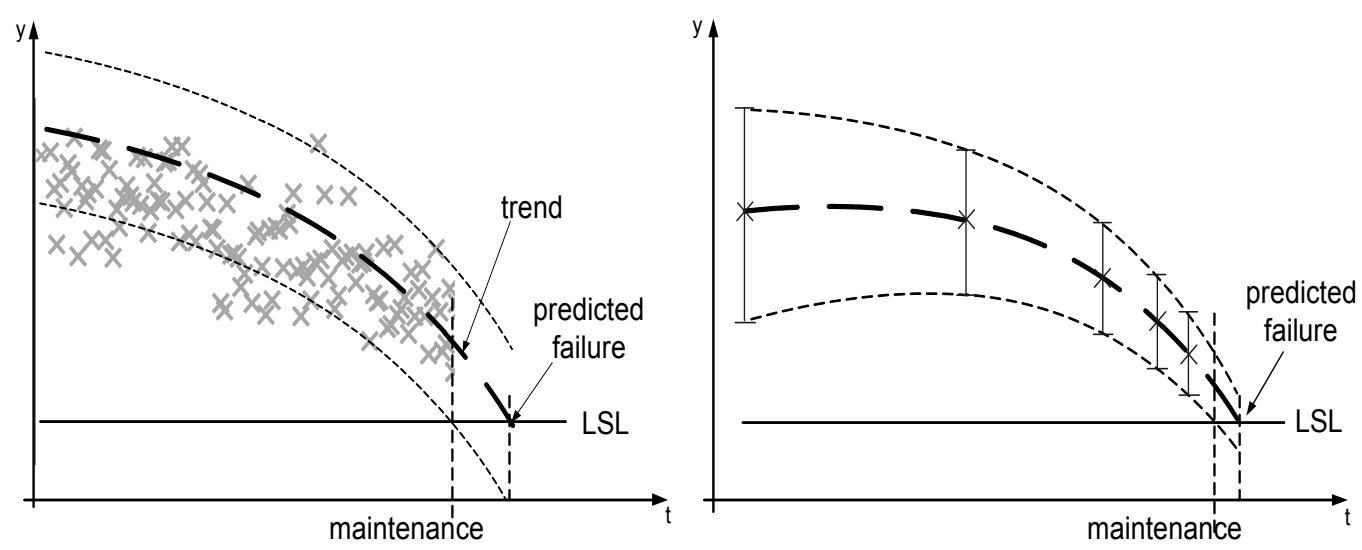

Figure 4: Confidence intervals of measured processes.

At a given confidence level the width of confidence interval can be decreased if the sampling frequency is increased when the trend comes closer to the LSL (right side of Figure 4). Increasing the frequency of sampling, the length of the confidence interval of forecasting will decrease. The length of the confidence interval (for a given significance level $\alpha$ ) can be calculated as follows:

$$
I N T_{1-\alpha}=\bar{y} \pm t_{1-\alpha / 2} \cdot \frac{\sigma}{\sqrt{n}} \cdot \sqrt{1-\frac{n}{N}}
$$

where $n$ is the size of the sample, $N$ is the number of the elements of the whole population, $\sigma$ is the uncertainty expressed as a standard deviation and $t$ is the value of Student- $t$ distribution that belongs to the confidence level of $1-\alpha / 2$.

After the decomposition we identify the stochastic process best fitting to the real process. Once we have identified a particular model we need to estimate the parameters and assess how well the model fits. After the validation of the stochastic model it can be used for forecasting. This model predicts the next value on the basis of actual and previous values of real process and prediction error. The further we try to forecast the higher the uncertainty will be (see Figure $5)$.

The optimal control limit can be determined by simulation or estimation with the methods shown in previous sections. This limit is not a constant as it changes with the time. At the time of the initial measurements the risk of decision error type II is low, because the observedcharacteristic is far from the LSL (see Figure 5). This risk is increasing because of the deterioration. The risk of decision error type $\mathrm{I}$ is also increasing but at a slower rate than the risk of decision error type II. So the curve of minimal total risk will increase. 


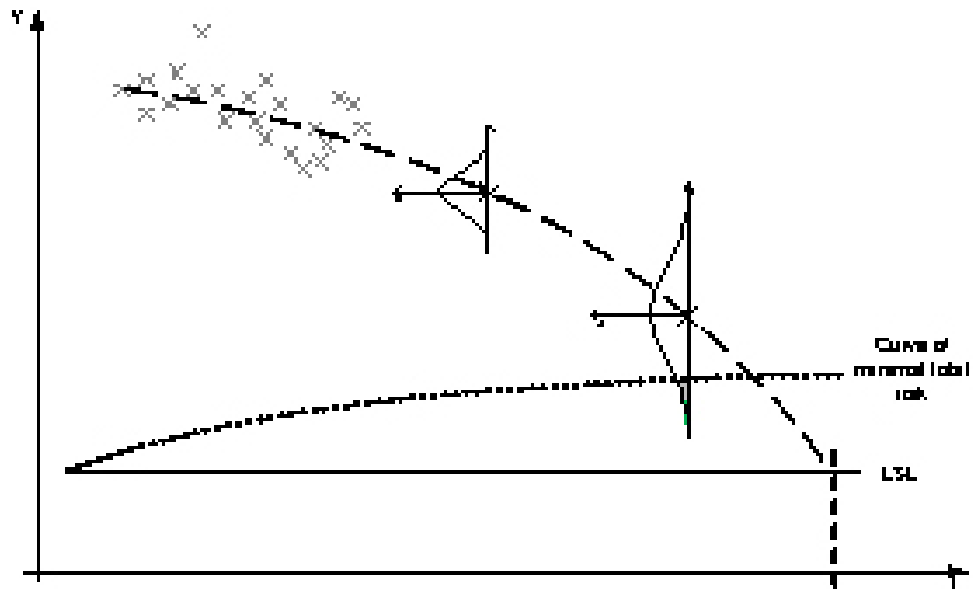

Figure 5: The uncertainty increases with the interval of forecast.

The following measurement must be performed there, where the confidence interval of forecast intersects the curve of minimal total risk $\left(t_{\mathrm{MI}}\right)$ (see Figure 6). Until this point failure will not occur in the process with the confidence level of forecast. With the new measurement result the decomposition, identification, estimation of parameters and forecast will be executed again. These steps are performed iteratively $\left(t_{\mathrm{M} 2}, t_{\mathrm{M} 3}\right)$ until the interval between intersection of the confidence interval and the curve of minimal total cost and the intersection of the confidence interval of the trend and the curve of minimal total risk is inessential. At this point maintenance is required as opposed to measurement.

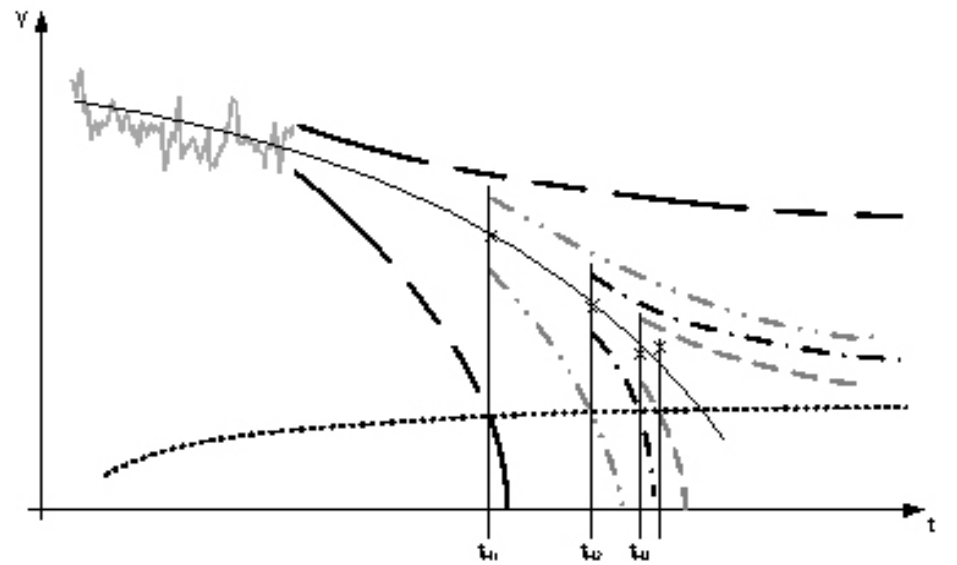

Figure 6: The intersections of confidence intervals and curve of minimal total risk determine the time of measurements

\section{Results of the Simulations and Calculations}

Simulations and calculations have been done to different types of distributions including continuous uniform, triangle and normal distributions (Table 2). There was only a lower specification limit; $L S L=52$. Two cases were considered: in the first case the loss of decision error type II was much (15 times) higher than the loss of decision error type I

. In the second case the loss of decision error type II was only twice as high as the loss of 
PROBLEMS

OF MANAGEMENT

IN THE $21^{\text {st }}$ CENTURY

Volume 1, 2011

decision error type I. (If the rate of these losses are below 1 then the corrective maintenance would be $\left(\pi_{0 I}-\pi_{00}\right)$ more efficient than the preventive maintenance.) Two relative costs $\left(\pi_{10}-\pi_{11}\right)$ were calculated:

$$
\begin{gathered}
c_{\text {sim }}\left(K_{\text {opt }}^{\text {sim }}\right)=\frac{C_{\text {sim }}\left(K_{o p t}^{\text {sim }}\right)}{C_{\text {sim }}(0)} \\
c_{\text {calc }}\left(K_{o p t}^{\text {calc }}\right)=\frac{C_{\text {calc }}\left(K_{\text {opt }}^{\text {calc }}\right)}{C_{\text {calc }}(0)}
\end{gathered}
$$

The $K_{o p t}^{\text {sim }}$ is the optimal correction factor determined by simulations; the $C_{\text {sim }}\left(K_{o p t}^{\text {sim }}\right)$

is the total cost in $K_{o p t}^{\text {sim }}$. The $K_{o p t}^{\text {calc }}$ and $C_{\text {calc }}\left(K_{o p t}^{\text {calc }}\right)$ the optimal correction factor and minimal total cost calculated analytically.

\begin{tabular}{|c|c|c|c|c|c|c|}
\hline $\begin{array}{l}\text { Distribution } \\
\text { of real values }\end{array}$ & $\begin{array}{l}\text { Distribution of } \\
\text { measurement } \\
\text { uncertainty }\end{array}$ & $\frac{\pi_{0 I}-\pi_{00}}{\pi_{10}-\pi_{1 I}}$ & $K_{o p t}^{\text {sim }}$ & $K_{\text {opt }}^{\text {calc }}$ & $\mathbf{c}_{\text {sim }}\left(K_{o p t}^{\text {sim }}\right)$ & $\mathbf{c}_{\text {calc }}\left(K_{o p t}^{\text {calc }}\right)$ \\
\hline \multirow{2}{*}{$\begin{array}{l}\text { uniform } \\
(50,70)\end{array}$} & \multirow{2}{*}{$\begin{array}{c}\text { uniform } \\
(-3,3)\end{array}$} & 15 & 2.6250 & 2.6393 & 0.2608 & 0.2614 \\
\hline & & 2 & 0.9798 & 0.9986 & 0.9593 & 0.9596 \\
\hline \multirow{2}{*}{$\begin{array}{c}\text { triangle } \\
(50,60,70)\end{array}$} & \multirow{2}{*}{$\begin{array}{c}\text { uniform } \\
(-3,3)\end{array}$} & 15 & 1.9693 & 2.1890 & 0.6821 & 0.6801 \\
\hline & & 2 & -1.6469 & -1.4563 & 0.7909 & 0.7839 \\
\hline \multirow{2}{*}{$\begin{array}{c}\text { normal } \\
(60,4.0825)\end{array}$} & \multirow{2}{*}{$\begin{array}{c}\text { uniform } \\
(-3,3)\end{array}$} & 15 & 1.9745 & 1.8341 & 0.6634 & 0.6628 \\
\hline & & 2 & -1.1109 & -0.9758 & 0.9024 & 0.8946 \\
\hline \multirow{2}{*}{$\begin{array}{l}\text { uniform } \\
(50,70)\end{array}$} & \multirow{2}{*}{$\begin{array}{l}\text { triangle } \\
(-3,0,3)\end{array}$} & 15 & 1.9484 & 1.9425 & 0.2981 & 0.2981 \\
\hline & & 2 & 0.4468 & 0.5038 & 0.9314 & 0.9300 \\
\hline \multirow{2}{*}{$\begin{array}{c}\text { triangle } \\
(50,60,70)\end{array}$} & \multirow{2}{*}{$\begin{array}{l}\text { triangle } \\
(-3,0,3)\end{array}$} & 15 & 1.3543 & 1.4005 & 0.5889 & 0.5815 \\
\hline & & 2 & -0.3438 & -0.2383 & 0.9768 & 0.9655 \\
\hline \multirow{2}{*}{$\begin{array}{c}\text { normal } \\
(60,4.0825)\end{array}$} & \multirow{2}{*}{$\begin{array}{l}\text { triangle } \\
(-3,0,3)\end{array}$} & 15 & 1.3264 & 1.2106 & 0.5772 & 0.5727 \\
\hline & & 2 & -0.1441 & -0.1947 & 0.9895 & 0.9719 \\
\hline \multirow{2}{*}{$\begin{array}{l}\text { uniform } \\
(50,70)\end{array}$} & \multirow{2}{*}{$\begin{array}{c}\text { normal } \\
(0,1.2247)\end{array}$} & 15 & 1.8698 & 1.8870 & 0.3244 & 0.3232 \\
\hline & & 2 & 0.5182 & 0.4801 & 0.9320 & 0.9319 \\
\hline \multirow{2}{*}{$\begin{array}{c}\text { triangle } \\
(50,60,70)\end{array}$} & \multirow{2}{*}{$\begin{array}{c}\text { normal } \\
(0,1.2247)\end{array}$} & 15 & 1.3016 & 1.1185 & 0.5879 & 0.5521 \\
\hline & & 2 & -0.2738 & -0.3504 & 0.9783 & 0.9770 \\
\hline
\end{tabular}

Table 2. The results of the simulations and analytical calculations. 
Csaba HEGEDÜS, Zsolt T. KOSZTYÁN. The Consideration of Measurement Uncertainty in Forecast and Maintenance Related Decisions

\begin{tabular}{|c|c|c|c|c|c|c|}
\hline normal & normal & 15 & 1.2436 & 1.2546 & 0.5818 & 0.5808 \\
\cline { 3 - 6 }$(60,4.0825)$ & $(0,1.2247)$ & 2 & -0.1438 & -0.1770 & 0.9921 & 0.9896 \\
\hline
\end{tabular}

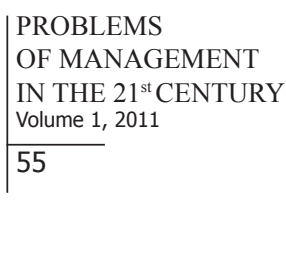

On Figure 7 profits are compared to each other as a result of simulations. The gray surface represents the profit $(\Pi(0))$ as a function of the process performance index when the acceptance limit is not altered. The black surface depicts the profit $(\Pi(K))$ when the acceptance limit is modified with $K$ in order to compensate the measurement uncertainty. Three typical solutions are in the practice: the measurement uncertainty is not taken into consideration $(K=0)$, the acceptance zone is tightened with the double of the standard deviation of measurement uncertainty ( $K=2 \sigma_{m}$ marked with white dash-dot line on Figure 7.A) or the acceptance zone is widened with the same extent $\left(K=-2 \sigma_{m}\right.$ marked with white dashed line on Figure 7.B). The optimal value of $K\left(K=K_{\text {opt }}\right)$ is delineated with white solid line, the profit is reached by using this optimal correction $\left(K_{\text {opt }}\right)$ of the acceptance limit is the highest reachable.

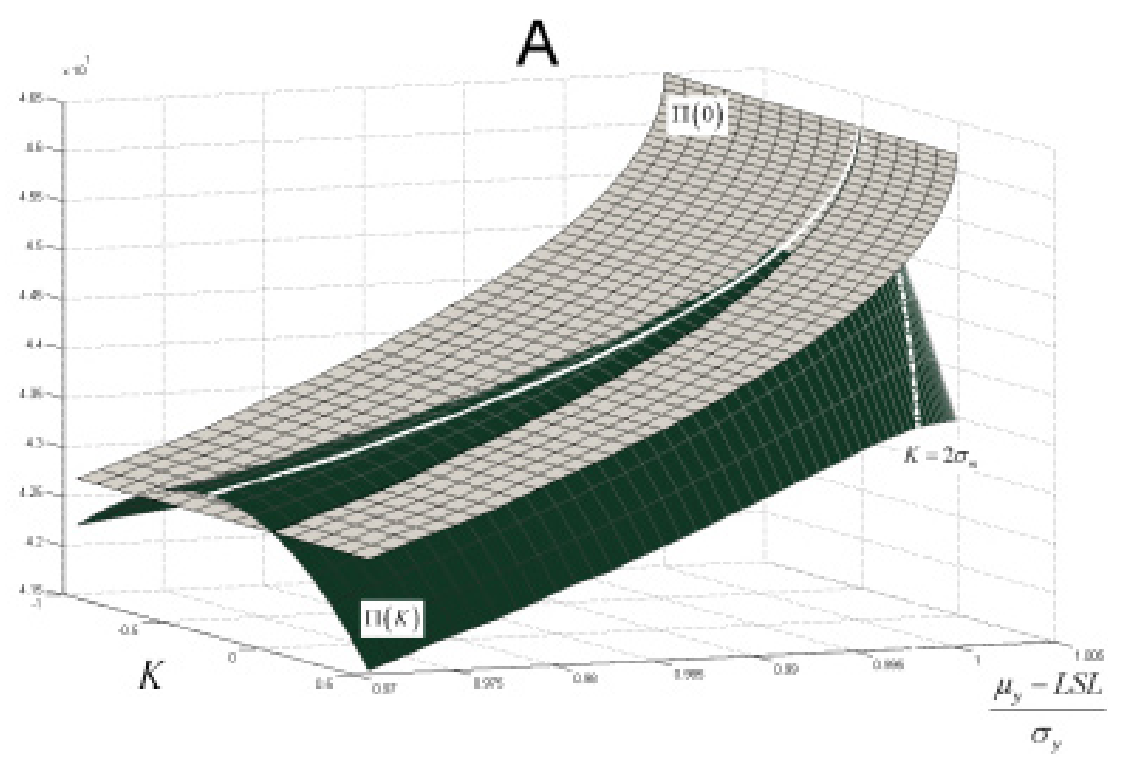

B

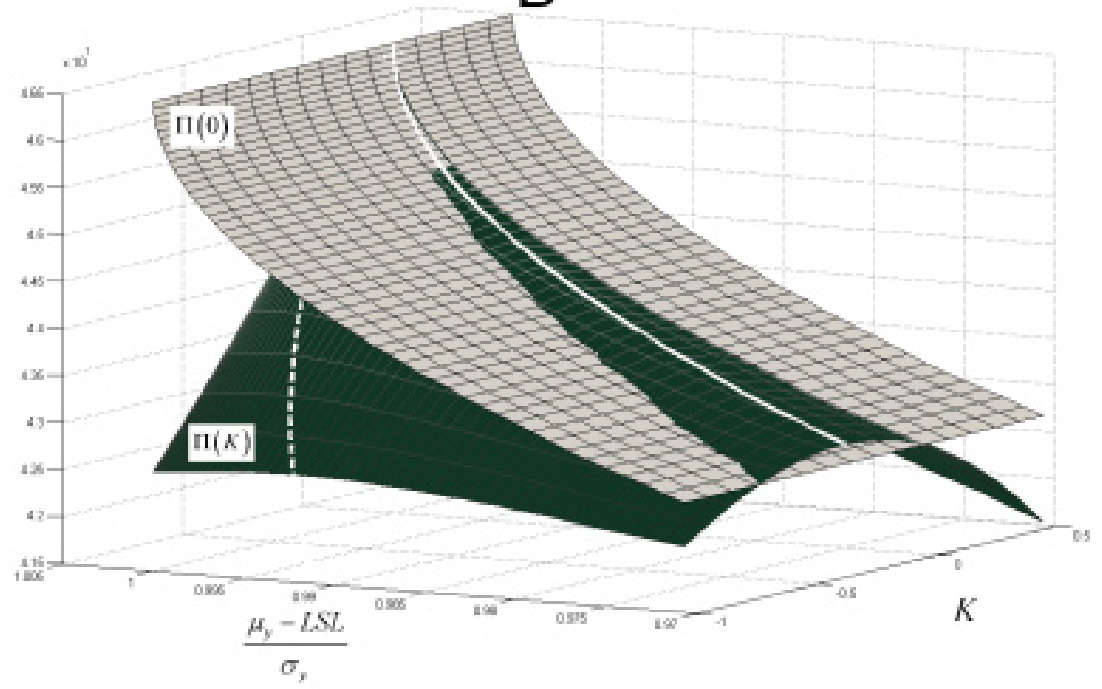

Figure 7: Comparison of profits when acceptance limit is modified and not modified. 
PROBLEMS

OF MANAGEMENT

IN THE $21^{\text {st }}$ CENTURY

Volume 1, 2011

In the case of forecast the curve of minimal total risk in reference to decisions was determined by simulations. The time series of the process could be decomposed to a trend and random effects according to the initial measurement. The trend decreased exponentially. The $y_{\mathrm{T}}$ was the value of the trend at the $t$-th measurement without random effect.

$$
y_{T}=2810-233.58 \cdot \exp \left(0.0021^{\prime} t\right)
$$

The ARIMA $(1,1,1)$ process was the identificated stochastic process that described the random effect in the real process. The parameters of ARIMA $(1,1,1)$ are in Table 3.

Table 3. The parameters of ARIMA model.

\begin{tabular}{|l|c|c|c|c|}
\hline Parameters & Estimate & SE & $\mathbf{t}$ & Sig. \\
\hline Constant Lag 1 & 0.043 & 0.302 & 0.141 & 0.888 \\
\hline AR & 0.682 & 0.043 & 15.994 & 0.000 \\
\hline Difference Lag 1 & 1 & & & \\
\hline MA & 0.903 & 0.025 & 35.828 & 0.000 \\
\hline
\end{tabular}

The confidence interval of forecast intersects the curve of minimal risk in the $t_{\mathrm{M}}$ point (Figure 8). This is the latest point in time the measurement must be performed. The interval between the last measured point and $t_{\mathrm{M} 1}$ corresponds to 125 measurment interval

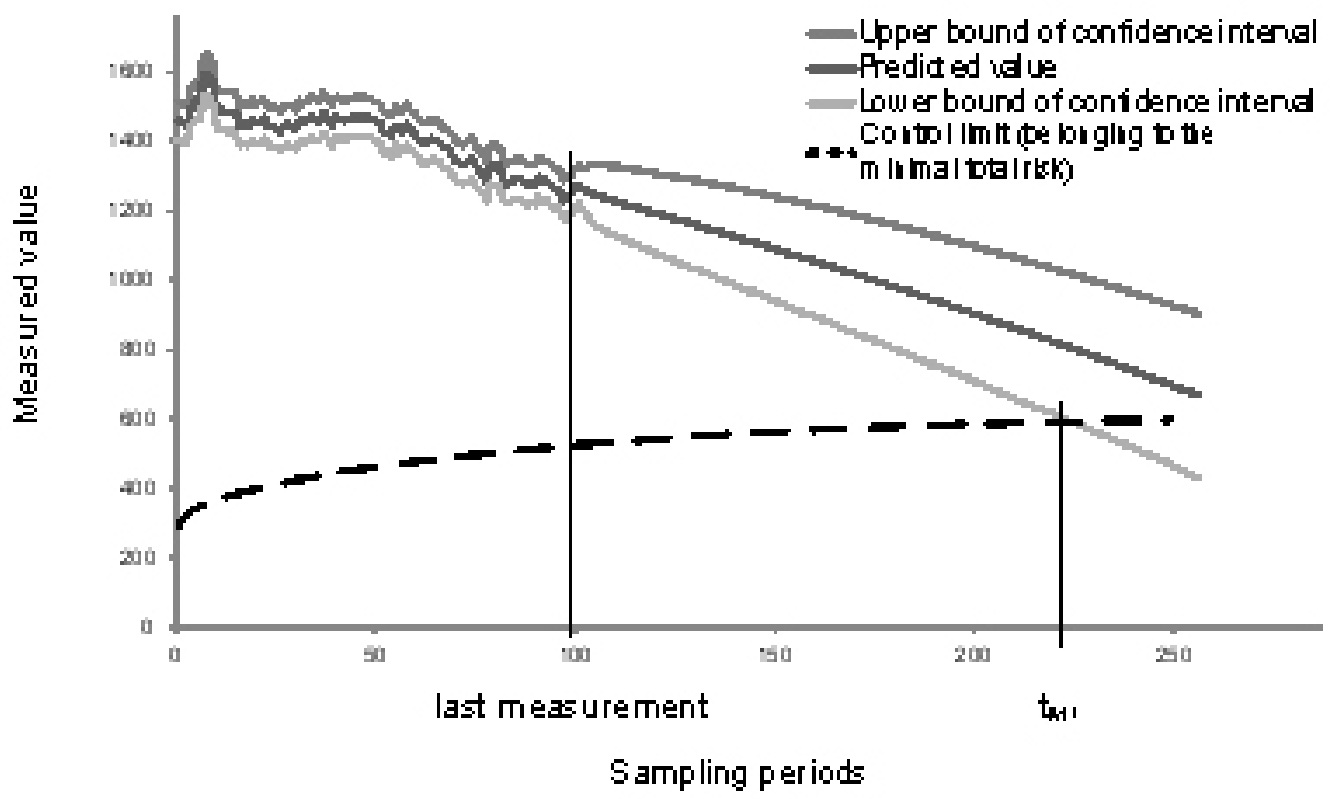

Figure 8: Forecast of the time of the next measurement.

In the case of condition based (predictive) maintenance after the initial transient phase and the identification of stochastic process, a considerable amount of inspection cost can be spared with the forecast. 


\section{Discussion}

In the practice, in technical reports and guides the measurement uncertainty is taken into account with a reliability centered approach. If the alteration of acceptance or control limits neglects the consequences of the decision errors, the loss can be higher than without the consideration of measurement uncertainty (see Figure 7.). The advised method unlike the previous ones uses a risk based approach that takes into account costs and revenues of the decision outputs. Thus it can minimize the loss or maximize the profit of a measurement based decision.

The introduced model can be used to determine the optimal control limit if the measurement error is independent from the real value of the process and the probability distribution of measurement uncertainty and the process can be determined. This model can be used to forecast the value of the process if the time series of the process is stationary or transformable to stationary (quasi-stationary). This method is worth using where the loss $\left(\pi_{10}-\pi_{1 I}\right)$ of decision error type II is higher than the loss $\left(\pi_{0 I}-\pi_{00}\right)$ of decision error type I. The suggested method combined with the forecast increases the profit if the costs of measurement are high and the continuous observation is not necessary. It can be developed to give the optimal control limit and time of linked devices on the basis of joint reliability and total cost of consequences.

\section{Conclusion}

The preventive maintenance decisions are based on measurement results, but these results have an uncertainty and cause incorrect decisions. It is necessary to take into account this uncertainty on a risk base. In this paper a uniform model was presented that treats the customer's risk along with the producer's risk through the consideration of the measurement uncertainty and costs or losses in reference to maintenance decisions. This model gives the optimal control limit of the process that minimizes the total risk associated with the decisions and maximizes the related profits. It can treat both kinds of the processes that have either only one or two specification limits. The optimal control limit influenced by the risks can be determined by Monte Carlo simulation or analytical calculation. The weakness of condition based maintenance is the difficulty of planning. If the process can be forecasted the proposed model gives the latest time when the next measurement must be performed, to minimize the cost of measurement but avoid threatening the operation of the device or the production process. Until this time, control is not necessary at a given level of confidence.

\section{Note}

This is a revised and enhanced version of an international scientific conference paper in Problems of Management in the 21st Century. The reference for the conference version is:

Csaba Hegedüs, Zsolt T. Kosztyán (2010): Treating measurement uncertainty in maintenance related decisions, $38^{\text {th }}$ ESReDA Seminar on Advanced Maintenance Modelling, Pécs, Hungary, 4-5 May 2010.

\section{References}

Åkesson, B. M., Toivonen, H. T. (2006). State-dependent parameter modelling and identification of stochastic non-linear sampled-data systems. Journal of Process Control, Vol. 16, No. 8, pp. 877-886.

Arunraj, N. S., Maiti, J. (2009). A methodology for overall consequence modeling in chemical industry. 


\begin{abstract}
PROBLEMS
OF MANAGEMENT

IN THE $21^{\text {st }}$ CENTURY

Volume 1, 2011

58 Journal of Hazardous Materials, 169, pp. 556-574.

BIPM, IEC, IFCC, ISO, IUPAC, IUPAP \& OIML (1993). Guide to the Expression of Uncertainty in Measurement. Geneva: International Organisation for Standardisation.

Chen, Z., Lu, S., Lam, S. (2007). A hybrid system for SPC concurrent pattern recognition. Advanced Engineering Informatics, 21, pp. 303-310.

Ellison, S. L. R., Williams, A. (2007). EURACHEM/CITAC Guide: Use of uncertainty information in compliance assessment. First Edition, Eurachem.

Forbes, A. B. (2006). Measurement uncertainty and optimized conformance assessment. Measurement, 39, pp. 808-814.

ILAC - International Laboratory Accreditation Cooperation (2009). ILAC-G8:03/2009: Guidelines on the Reporting of Compliance with Specification. Silverwater, Australia: ILAC Secretariat.

ISO - International Organisation for Standarsitation (1998). ISO 14253-1:1998. Geometrical Product Specification (GPS)-Inspection by measurement of workpieces and measuring instruments-Part I: Decision rules for proving conformance or non-conformance with specifications, Geneva: International Organisation for Standardisation.
\end{abstract}

Kosztyán Zs. T., Schanda, J. (2006). Flatbed scanners and CCD-cameras: colorimetric characterization and uncertainties. 2nd Expert Symposium on Measurement Uncertainty, June 11 - 17, pp. 219-228.

Kosztyán, Zs. T., Csizmadia, T., Hegedüs, Cs., Kovács, Z. (2009). A new approach to forecasting conformity treating measurement uncertainty in SPC. AVA (International Congress on the Aspects and Vision of Applied Economics and Informatics), Debrecen, Hungary 26 March 2009.

Kosztyán, Zs. T., Csizmadia, T., Hegedüs, Cs. \& Kovács, Z. (2010). Treating measurement uncertainty in complete conformity control system. Innovations and Advances in Computer Sciences and Engineering (edited by Tarek Sobh) Springer Netherlands, pp. 79-84.

Krishnasamy, L., Khan, F., Haddara, M. (2005). Development of a risk-based maintenance (RBM) strategy for a power-generating plant. Journal of Loss Prevention in the Process Industries, 18, pp. 69-81.

Pendrill, L. R. (2006): Optimised measurement uncertainty and decision-making when sampling by variables or attribute. Measurement, 39, pp. 829-840.

Pintelon, R., Schoukens, J. (2006). Box-Jenkins identifications revisited, Part I: Theory. Automatica, 42, pp. 63-75.

Rossi, G., Crenna, F. (2006). A probabilistic approach to measurement-based decisions. Measurement, 39, pp. 101-119.

Advised by Zoltan Kovacs, University of Pannonia, Veszprém, Hungary

Received: May 18, 2011

Accepted: May 27, 2011 
Csaba HEGEDŰS, Zsolt T. KOSZTYÁN. The Consideration of Measurement Uncertainty in Forecast and Maintenance Related Decisions

PROBLEMS

OF MANAGEMENT

IN THE $21^{\text {st }}$ CENTURY

Volume 1, 2011

59

Csaba Hegedüs

Ph.D., Student, University of Pannonia, Department of Management, Egyetem u.

10, Veszprém, Hungary.

E-mail: hegeduscs@gtk.uni-pannon.hu

Website: http://englishweb.uni-pannon.hu/

Zsolt Tibor Kosztyán

Ph.D., Associate Professor, University of Pannonia, Department of Quantitative Methods, Egyetem u. 10, Veszprém, Hungary.

E-mail: kzst@vision.vein.hu

Website: http://englishweb.uni-pannon.hu/ 